\title{
Débora Garazi. El revés de las vacaciones: hotelería, trabajo y género. Mar del Plata, segunda mitad del siglo XX. Bernal: Universidad Nacional de Quilmes, 2020, $387 \mathrm{pp}$.
}

\author{
Graciela Queirolo*
}

En las sociedades modernas, las vacaciones se conformaron como un tiempo de Cocio para el descanso y el esparcimiento. En la Argentina, Mar del Plata, balneario ubicado en el sudeste de la provincia de Buenos Aires, devino un destacado centro de veraneo que, si bien tuvo un origen social elitista, vivió un proceso de democratización hasta llegar a convertirse, al promediar el siglo XX, en una capital del turismo de masas, cuya cara oculta fue un extenso mundo laboral. En El revés de las vacaciones, Débora Garazi estudia el trabajo hotelero, en la ciudad de Mar del Plata, durante la segunda mitad del siglo XX, preguntándose por las experiencias laborales de sus protagonistas.

Este libro, producto de una investigación doctoral financiada por el sistema científico público argentino, se escribe desde la historia social y los estudios de género. Su primer logro es estudiar el mundo del trabajo a través de los procesos laborales que incluyen tanto los espacios y los tiempos como las tareas y los saberes involucrados, así como también tres dimensiones muy particulares como son la económica, la temporal y la emocional; es decir, la autora elige un camino distante del universo sindical y las acciones colectivas, lo cual no significa que desestime ni a las organizaciones gremiales ni a las protestas. Su segundo logro radica en ahondar en las relaciones de género atendiendo tanto a la segregación ocupacional entre personas - mujeres y varones- como a los sentidos implícitos en las tareas.

Garazi construye su análisis en torno a un corpus de entrevistas realizadas a antiguas y antiguos trabajadores hoteleros que combina con una enorme cantidad de materiales diversos, como manuales de hotelería, prensa comercial, censos de población, documentos legislativos, convenios colectivos de trabajo, sentencias judiciales y fotografias. Asimismo, la autora recurre a categorías analíticas de la sociología del trabajo y de la economía feminista que utiliza de manera sofisticada

* Profesora adjunta e investigadora del Centro Interdisciplinario de Investigaciones en Género, Universidad Nacional de La Plata, Consejo Nacional de Investigaciones Científicas y Técnicas (Conicet), Argentina. 
para desplegar sus propios argumentos, tal es el caso de la oposición entre trabajo y empleo (Margaret Maruani); de sociedad salarial (Robert Castel), de trabajo emocional (Arlie Hochschild); de las diferencias entre tiempo doméstico y tiempo privado (Soledad Murillo) o entre calificación/saber y cualificación/empirismo (Enrique de la Garza Toledo y Judy Wajcman). Con semejantes posicionamiento, insumos y herramientas, la autora organiza el libro en seis capítulos. En los tres primeros, presenta las generalidades del trabajo hotelero.

Los movimientos migratorios internacionales y nacionales atraídos por las demandas de la actividad turística que se volvía exponencial durante la época estival dieron vida al mercado de trabajo. Grandes establecimientos de gestión estatal o privada junto con modestos hospedajes administrados por una familia demandaron los servicios de mujeres y varones. Se trató de actividades abordadas en el capítulo 1 que, en su mayoría, solo requerían habilidades simples junto a una buena predisposición para adquirirlas (saber hacer), es decir, tareas muy atractivas para quienes buscaran trabajo porque se aprehendían en poco tiempo por repetición e imitación (saberes empíricos).

La dimensión económica del trabajo hotelero tuvo como principal característica una remuneración que combinaba un salario básico con el laudo gastronómico, suma calculada a partir de un porcentaje del total de la facturación del establecimiento. La regulación del laudo, producto de numerosos conflictos, asignó al trabajo hotelero la calidad de empleo asalariado porque limitó no solo la discrecionalidad de los empleadores, sino también la exclusividad de la propina y otorgó una identidad específica a todos sus miembros dentro del mercado de trabajo, tal como se estudia en el capítulo 2.

Otros dos aspectos centrales constitutivos del trabajo hotelero fueron la estacionalidad y el carácter relacional, estudiados en el capítulo 3. La estacionalidad, diferenció sus ocupaciones de la continuidad anual presente en otras y obligó a sus trabajadoras y trabajadores a la búsqueda de la conciliación con otras actividades económicas. Para los varones, el empleo durante la temporada estival debía conciliarse con otras tareas asalariadas durante los demás meses — cuando la temporada finalizaba, los establecimientos solo retenían una reducida proporción de la planta- porque para ellos, el empleo remunerado se asimiló a la figura del proveedor material. En cambio para las mujeres, el trabajo hotelero durante el verano les permitió la conciliación con las tareas reproductivas, propias de su identidad femenina maternal, a las que se consagraban los demás meses del año, puesto que el empleo asalariado se consideró un suplemento ocasional y temporario.

Respecto al carácter relacional del trabajo hotelero, Garazi postula la presencia de un trabajo emocional. En efecto, "prestar un servicio" exigía una correcta y eficiente atención de las y los turistas cuya contraparte podía compensarse con la recepción de propinas, una retribución monetaria voluntaria que, aunque desde la reglamentación del laudo estaba prohibida, era implícita y frecuente y sumaba a los ingresos definitivos de las y los trabajadores pero también habilitaba la posibilidad de tratos arbitrarios. Sin embargo, la autora demuestra que las y los 
trabajadores hoteleros al ejercer un trabajo asalariado en el espacio público pudieron limitar las peticiones caprichosas de las y los pasajeros a diferencia del personal de servicio doméstico cuyas actividades, al transcurrir en un espacio privado ajeno, las y los volvía más vulnerables. Así, el trabajo hotelero se caracterizó no solo por un saber hacer sino fundamentalmente un saber ser propio de una persona que prestaba un servicio a otra con los reparos indicados.

Los tres capítulos restantes estudian la segregación genérica de las ocupaciones del trabajo hotelero. Esta consiste en una división técnica de las ocupaciones donde intervinieron sentidos generizados. Entonces, el libro indaga en el capítulo 4 en la recepción, un espacio ampliamente masculinizado. Allí, se encontraban los maleteros o botones - designación originada en la abundante cantidad de botones en los uniformes-, personal que integraba la base de la pirámide de ocupaciones, así como también se desempeñaron los recepcionistas y conserjes, personal de cierta jerarquía, responsables de la gestión administrativa. Unos y otros fueron la cara visible del personal hotelero, quienes interactuaban con las y los pasajeros. Aquí, las mujeres solo tuvieron reservada la posición de operadora telefónica cuyo contacto con el conmutador, un aparato complejo, las jerarquizó respecto de otras ocupaciones de mujeres.

Luego el libro incursiona en el capítulo 5 en las habitaciones y los pisos, un espacio feminizado donde las mucamas desplegaron unas tareas consideradas innatas de su condición femenina como fueron las domésticas (limpieza y orden), al tiempo que adquirieron un aspecto invisible porque cuando ellas realizaban su trabajo, las y los pasajeros estaban ausentes. A pesar de que ni el mercado ni las protagonistas reconocieron el valor de su saber hacer, Garazi subraya, la habilidad y el ingenio que ellas desplegaron para que sus tareas se lucieran, como el uso de determinados productos para resaltar la limpieza. La feminización del sector excedió a las personas, según demuestra la autora cuando presenta el caso de un varón mucamo tildado de homosexual por sus compañeras porque realizaba un supuesto trabajo de mujer.

Finalmente, el libro se detiene en la cocina en el capítulo 6, donde brillaron los chef, y en el comedor, donde los mozos transportaban los pedidos de la cocina a las mesas. Nuevamente los sentidos de género lucen su arbitrariedad porque una misma actividad, cocinar, recibía sentidos diferentes según el lugar en que se realizaba. Cuando la cocina era una tarea doméstica, se trataba de una tarea de mujer, por lo tanto, no se le reconocía ninguna calificación ni remuneración, pero cuando era una tarea hotelera devenía una profesión de varón. El chef fue un profesional de la cocina con un saber certificado, prestigioso y considerablemente remunerado.

Para concluir diré que, a la reconstrucción y caracterización del trabajo hotelero desplegadas a lo largo del libro, el análisis de Garazi incorpora el problema de cómo definir el trabajo porque cuestiona las concepciones androcéntricas que no solo privilegiaron el análisis exclusivo del empleo asalariado e ignoraron el examen del trabajo reproductivo, sino que, además, se focalizaron en el empleo continuo o de tiempo completo, desestimando el análisis de modalidades como las 
encontradas en la hotelería. Asimismo, la autora demuestra que el trabajo hotelero consiste en un trabajo reproductivo que transcurre en el mundo público bajo particulares condiciones asalariadas y, por ende, ese trabajo apuntalaba el descanso de muchas otras personas: "no quedaba otra, cuando la gente se divertía vos estabas trabajando" (p. 158), resumirá uno de sus entrevistados. Sugestiva conclusión que pondera la importancia que las tareas reproductivas adquieren para la organización social de la vida en todas sus dimensiones. Por último, El revés de las vacaciones es una invitación a pensar una periodización para la sociedad salarial desde la perspectiva argentina, porque a lo largo de sus páginas sobrevuela la idea de que la sociedad salarial que terminó de definir el peronismo clásico (1946-1955) atravesó la segunda mitad del siglo XX para comenzar su veloz ocaso con el peronismo neoliberal (1989-1999).

DOI: $10.17533 /$ udea.trahs.n18a14 